\title{
SimSphere model sensitivity analysis towards establishing its use for deriving key parameters characterising land surface interactions
}

\author{
G. P. Petropoulos ${ }^{1}$, H. M. Griffiths ${ }^{1}$, T. N. Carlson ${ }^{2}$, P. Ioannou-Katidis ${ }^{1}$, and T. Holt ${ }^{1}$ \\ ${ }^{1}$ Department of Geography and Earth Sciences, Aberystwyth University, Aberystwyth, SY23 2DB, UK \\ ${ }^{2}$ Department of Meteorology, Pennsylvania State University, University Park, PA 16802, USA
}

Correspondence to: G. P. Petropoulos (george.petropoulos@ aber.ac.uk)

Received: 2 October 2013 - Published in Geosci. Model Dev. Discuss.: 7 January 2014

Revised: 25 June 2014 - Accepted: 25 June 2014 - Published: 2 September 2014

\begin{abstract}
Being able to accurately estimate parameters characterising land surface interactions is currently a key scientific priority due to their central role in the Earth's global energy and water cycle. To this end, some approaches have been based on utilising the synergies between land surface models and Earth observation (EO) data to retrieve relevant parameters. One such model is SimSphere, the use of which is currently expanding, either as a stand-alone application or synergistically with EO data. The present study aimed at exploring the effect of changing the atmospheric sounding profile on the sensitivity of key variables predicted by this model assuming different probability distribution functions (PDFs) for its inputs/outputs. To satisfy this objective and to ensure consistency and comparability to analogous studies conducted previously on the model, a sophisticated, cuttingedge sensitivity analysis (SA) method adopting Bayesian theory was implemented on SimSphere. Our results did not show dramatic changes in the nature or ranking of influential model inputs in comparison to previous studies. Model outputs examined using SA were sensitive to a small number of the inputs; a significant amount of first-order interactions between the inputs was also found, suggesting strong model coherence. Results showed that the assumption of different PDFs for the model inputs/outputs did not have an important bearing on mapping the most responsive model inputs and interactions, but only the absolute SA measures. This study extends our understanding of SimSphere's structure and further establishes its coherence and correspondence to that of a natural system's behaviour. Consequently, the present work represents a significant step forward in the global efforts on SimSphere verification, especially those focusing on the development of global operational products from the model synergy with EO data.
\end{abstract}

\section{Introduction}

Understanding the natural processes of the Earth as well as how the different components (i.e. lithosphere, hydrosphere, the biosphere and atmosphere) of the Earth's systems interplay, especially in the context of global climate change, has been recognised by the global scientific community as a very urgent and important research direction requiring further investigation (Battrick et al., 2006). This requirement is also of crucial importance for addressing directives such as the EU Water Framework Directive. To this end, being able to accurately obtain spatio-temporal estimates of parameters such as the latent (LE) and sensible $(H)$ heat fluxes as well as of soil moisture is of great importance. This is due to their important role in many physical processes characterising land surface interactions of the Earth system as well as their practical use in a wide range of multidisciplinary studies and applications (Kustas and Anderson, 2009; Seneviratne et al., 2010).

As a result, deriving information on the spatio-temporal distribution of these parameters has attracted the attention of scientists from many disciplines. Over the past few decades, a wide variety of approaches for their retrieval have been proposed operating at different observation scales, including data sets from ground instrumentation, simulation models and Earth observation (EO). Recent studies have also focused on exploring the synergies between EO data and land surface process models (see reviews by Olioso, 1992 and Petropoulos and Carlson, 2011). Essentially, these techniques endeavour to provide improved predictions by combining the horizontal coverage and spectrally rich content of EO data with the vertical coverage and excellent temporal resolution of simulation process models. 

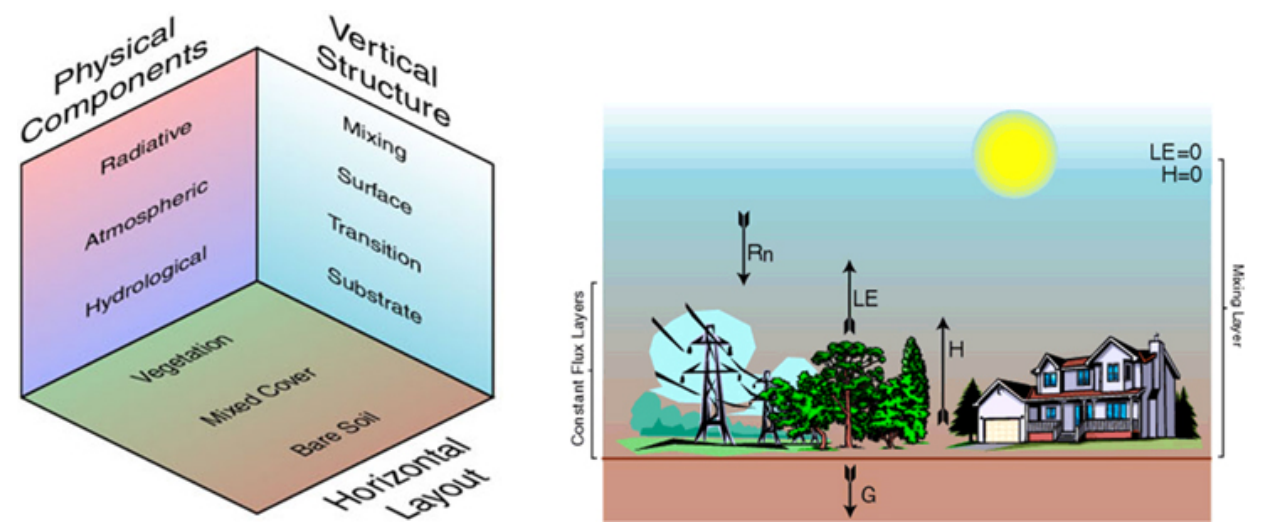

Figure 1. Left: the different layers of the SVAT model in the vertical domain; right: a schematic representation of the surface energy balance components computation in the SVAT model (after SimSphere user's manual available at http://www.aber.ac.uk/en/iges/research-groups/ earth-observation-laboratory/simsphere/workbook/preface/).

One such group of approaches, the so-called "triangle" method (Carlson, 2007), is used to predict regional estimates of LE, $H$ fluxes and soil moisture content (SMC). SimSphere is a soil-vegetation-atmosphere-transfer (SVAT) model, originally developed by Carlson and Boland (1978) and considerably modified to its current state by Gillies et al. (1997) and Petropoulos et al. (2013a). SVAT models are essentially mathematical representations of one-dimensional "views" of the physical mechanisms controlling energy and mass transfers in the soil-vegetation-atmosphere continuum, providing deterministic estimates of the time course of various variables characterising land surface interactions at time steps appropriate to the dynamics of atmospheric processes (Olioso et al., 1999). An overview of SimSphere use was recently provided by Petropoulos et al. (2009a). The different facets of the SVAT model's overall structure - namely the physical, the vertical and the horizontal - are illustrated in Fig. 1 (left). An extensive mathematical description of the model can be found in Carlson and Boland (1978), Carlson et al. (1981) and Gillies and Carlson (1995). The SimSphere model is maintained and is distributed freely globally (both the executable version and model code) from Aberystwyth University, United Kingdom (http://www.aber.ac.uk/ simsphere).

As regards the triangle method in particular, it has its foundations in the physical properties encapsulated in a satellitederived scatterplot of surface temperature $\left(T_{\mathrm{S}}\right)$ and vegetation index (VI), linked with SimSphere. Petropoulos et al. (2009b) have underlined the potential of this group of approaches for operational implementation in deriving estimates of $\mathrm{LE} / H$ fluxes and/or SMC. A recent description of the triangle workings can be found in Petropoulos and Carlson (2011). At present, variants of this method are explored - or even some already implemented in practice for deriving, in some cases operationally and on a global scale, estimates of LE and $H$ fluxes and/or SMC (Chauhan et al., 2003; Piles et al., 2011; ESA STSE, 2012). In addition,
SimSphere use is continually expanding worldwide both as an educational and as a research tool - used either as a standalone application or synergistically with EO data - to conduct studies aiming to improve understanding of land surface processes and their interactions. Considering the research and practical work with respect to SimSphere use, it is evidently of primary importance to execute a variety of validatory tests to evaluate its adequacy and coherence in terms of its ability to accurately and realistically represent Earth's surface processes.

Performing a sensitivity analysis (SA) provides an important and necessary validatory component of any computer simulation model or modelling approach before it is used in performing any kind of analysis. SA allows determining the effect of changing the value of one or more input variables of a model and observing the consequence that this has on given outputs simulated by the model. Its implementation on a model allows understanding the model's behaviour, coherence and correspondence to what it has been built to simulate (Saltelli et al., 1999, 2000; Nossent et al., 2011). As such, SA provides a valuable method to identify significant model inputs as well as their interactions and rank them (Chen et al., 2012), offering guidance to the design of experimental programs as well as to more efficient model coding or calibration. Indeed, by means of a SA unrelated parts of the model may be dropped or a simpler model can be built or extracted. The latter can reduce, in some cases significantly, the required computing power while maintaining the models' correspondence to a natural system's behaviour in the real world (Holvoet et al., 2005).

A range of SA approaches have been proposed, a comprehensive overview of which can be found for example in Saltelli et al. (2000). One group includes the so-called global SA (GSA) methods. These techniques aim to apportion the output variability to the variability of the input parameters when they vary over their whole uncertainty domain, generally described using probability densities assigned to the 
model's inputs. The sensitivity of the input parameters is examined based on the use of samples derived directly from the model, which are distributed across the parameter domain of interest. These methods, despite their high computational demands, have become popular in environmental modelling due to their ability to incorporate parameter interactions and their relatively straightforward interpretation (Nossent et al., 2011). They also account for the influence of the input parameters over their whole range of variation, which in turn enables obtaining SA results independent of any "modelers' prejudice", or site-specific bias (Song et al., 2012).

Petropoulos et al. (2009a) in a recent review of SimSphere exploitation underlined the importance of carrying out SA experiments on the model, as part of its overall verification. In response, Petropoulos et al. (2009c, 2010, 2013b, c, d) performed advanced GSA on SimSphere based on a Gaussian process (GP) emulator. As previous SA studies on SimSphere had been scarce, their results provided for the first time an insight into the model architecture, allowing the mapping of the sensitivity between the model inputs and key model outputs. Although all the model input parameters were varied across their full range of variation by those studies, a particular atmospheric sounding setting had been used in these GSA experiments by the authors. In addition, the effect of different probability distribution functions (PDFs) for the model inputs/outputs to the obtained had not been adequately explored.

In this context, the aim of the present study was to perform a GSA on SimSphere using an atmospheric sounding derived from a different region and evaluate the effect of atmospheric sounding on the SA results obtained on SimSphere assuming different PDFs for the model inputs/outputs. This will allow us to extend our understanding of this model structure and further establishing its coherence.

\section{The Bayesian sensitivity analysis method}

To satisfy the objectives of this study and to ensure consistency and comparability of our work to previous studies on SimSphere, SA is conducted here by employing a sophisticated, cutting-edge GSA method adopting Bayesian Analysis of Computer Code Outputs (BACCO; Kennedy and O'Hagan, 2001). It is implemented using the Gaussian Emulation Machine (GEM)-SA software, the development of which was funded by the National Environmental Research Council, United Kingdom. The theory behind the BACCO GEM-SA technique can be found by Oakley and O'Hagan (2004); detailed descriptions of the mathematical principles governing the GP emulation are available in Kennedy and O'Hagan (2001), Kennedy (2004) and Oakley and O'Hagan (2004). The use of the GPs to model unknown functions in Bayesian statistics dates back to Kimeldorlf and Wahba (1970) and O'Hagan (1978).
Briefly, BACCO GEM-SA implementation consists of two phases: first, a statistically based representation (i.e. an emulator) of the model is built from training data obtained from simulations derived from the actual model, which have been designed to cover the multidimensional input space using a space-filling algorithm. Second, the emulator itself is used to compute a number of statistical parameters to characterise the sensitivity of the targeted model output in respect to its inputs.

BACCO SA implementation starts from a prior belief about the code (i.e. that it has no numerical error), and then based on a GP model, Bayes' theorem and a set of the model code runs - this assumption is refined to yield the posterior distribution of the output, which is the emulator. In building the emulator, the most important prior assumption is that the output emulator is a reasonably smooth function of its inputs. On this basis, the emulator is used to calculate a mean function, which attempts to pass through the observed runs at the same time it quantifies the remaining uncertainty due to the emulator being an approximation to the true code. Within BACCO, various statistical measures are generated automatically when the emulator is built in order to check the accuracy of both types of output.

In simple mathematical terms, the basic SA output from GEM-SA includes a direct decomposition of the model output variance into factorial terms, called "importance measures" (e.g. Ratto et al., 2001):

$$
\begin{aligned}
V(Y) & =\sum_{i=1}^{s} D_{i}+\sum_{i \triangleleft j} D_{i j}+\ldots+D_{1 \ldots s} \\
D_{i} & =V\left(E\left(Y \mid X_{i}\right)\right), \\
D_{i j} & =V\left(E\left(Y \mid X_{i}, X_{j}\right)\right)-V\left(E\left(Y \mid X_{i}\right)\right) \\
& -V\left(E\left(Y \mid X_{j}\right)\right),
\end{aligned}
$$

where $s$ denotes the number of inputs (so-called "factors"), $-V(Y)$ is the total variance of the output variable $Y, D_{i}$ is the importance measure for input $X_{i}, D_{i j}$ is the importance measure for the interaction between inputs $X_{i}$ and $X_{j}, D_{1 \ldots s}$ denote similar formulae for the higher-order terms. $E\left(Y \mid X_{i}\right)$ is the conditional expectation of $Y$ given a value of $X_{i}$ and the variance of $E\left(Y \mid X_{i}\right)$ is taken over all inputs factors which are fixed in the conditional expectations.

In addition, in the BACCO method, sensitivity indices are computed by dividing the importance measures from Eq. (1) by the total output variance as follows:

$S_{i}=\frac{D_{i}}{V(Y)} \quad, \quad S_{i j}=\frac{D_{i j}}{V(Y)}$.

These ratios $S_{i}$ for $i=1, \ldots, s$ are called main effects or first-order sensitivity indices, because each $S_{i}$ delivers a direct measure of the share of the output variance explained by $X$. The main effect or first-order sensitivity index $S_{i}$ is the expected amount of variance that would be removed from the total output variance if the true value of $X_{i}$ were known 
(within its uncertainty range). Thus, this is a measure that quantifies the relative importance of an individual input variable $X_{i}$, in driving the total output uncertainty, indicating where to direct future efforts to reduce that uncertainty. Using similar formulae, higher-order sensitivity indices (joint effect indices) are also computed in GEM-SA to compute the sensitivity of the model output to input parameter interactions. However, in practice, because the estimation of $S_{i}$ or $S_{i j}$, or higher order, can be computationally very expensive, the SA is rarely carried out further after the computation of first-order interaction indices (i.e. the second term of Eq. 5 below). This is also the case with GEM-SA.

Thus, from the definitions of the above indices, and assuming non-correlated inputs, a complete series development of the output variance can be achieved:

$\sum_{i} S_{i}+\sum_{i \triangleleft j} S_{i j}+\sum_{i \triangleleft j \triangleleft m} S_{i j m}+\ldots+S_{12 \ldots k}=1$,

where higher-order indices are defined in a similar way to Eq. (7). This decomposition of variance into main effects and interactions is commonly known as analysis of variancehigh-dimensional model representation (HDMR).

The percentage variance contribution of each input's main effect is also reported in BACCO, providing a simple means of ranking the inputs in terms of their importance. The percentage variance component associated with each input measures the amount its main effect contributes to the total output variance, based on the uncertainty distributions for all inputs. It should be noted that, in general, summing the main effect contributions will not total to $100 \%$ because of the additional contributions from the interaction effects. However, the total can be used to determine the degree of interactions.

In addition to the above indices, another measure that is computed in GEM-SA is the total sensitivity index. This is used to provide a cheaper computational method of investigating the higher-order sensitivity effects as it collects all the interactions involving $X_{i}$ in one single term. The total sensitivity index of a given factor $X_{i}$ takes into account the main effect and the effect of all its interactions with other model inputs, and is defined as

$\mathrm{ST}_{i}=\frac{D_{i}+D_{i, \sim i}}{V(Y)}$,

where $D_{i, \sim i}$ indicates all interactions between factor $X_{i}$ and all the others $\left(X_{\sim i}\right)$.

The total sensitivity index represents the expected amount of output variance that would remain unexplained (residual variance) if only $X_{i}$ were left free to vary over its range, the value of all other variables being known. The usefulness of the $\mathrm{ST}_{i}$ is that it is possible to compute them without necessarily evaluating the single indices $S_{i}$ (and higherorder ones), making the analysis computationally affordable. The total sensitivity indices are generally used to identify unessential variables (i.e. those that have no importance either singularly or in combination with others) while building a model. The existence of large total effects relative to main effects implies the presence of interactions among model inputs.

The BACCO method has already supplied useful insights in various disciplines and in various SA studies underlying the advantages of this approach (Kennedy and O'Hagan, 2001; Johnson et al., 2011; Kennedy et al., 2012; Parry et al., 2012). Petropoulos et al. (2009c) demonstrated for the first time the use of the BACCO method in performing a SA on SimSphere, providing an insight into the model structure. Petropoulos et al. (2010) performed a comparative study of various emulators including BACCO GEM, investigating the effect of sampling method and size on the sensitivity of key target quantities simulated by SimSphere. Their results showed that the sampling size and method did affect the SA results in terms of absolute values, but had no bearing in identifying the most sensitive model inputs and their interactions, for model outputs on which SA was performed.

\section{Sensitivity analysis implementation}

To ensure consistency and comparability with previous analogous SA studies on SimSphere, the BACCO GEM-SA was implemented herein along the lines of previous similar GSA studies applied to that model (Petropoulos et al., 2009c, $2010,2013 b, c, d)$. The only difference was the use of a different atmospheric sounding profile derived from a different location and season. Thus, the sensitivity of the following SimSphere outputs was evaluated:

- Daily Average Net Radiation $\left(\overline{\operatorname{Rn}_{\text {daily }}}\right)$,

- Daily Average Latent Heat flux ( $\left.\overline{\mathrm{LE}_{\text {daily }}}\right)$,

- Daily Average Sensible Heat flux $\left(\overline{H_{\text {daily }}}\right)$,

- Daily Average Tair ( $\overline{\text { Tair }_{\text {daily }}}$ ),

- Daily Average Surface Moisture Availability $\left(\overline{\mathrm{Mo}_{\text {daily }}}\right)$,

- Daily Average Evaporative Fraction $\left(\overline{\mathrm{EF}_{\text {daily }}}\right)$,

- Daily Average Non-Evaporative Fraction $\left(\overline{\mathrm{NEF}_{\text {daily }}}\right)$,

- Daily Average Radiometric Temperature ( $\left.\overline{\operatorname{Trad}_{\text {daily }}}\right)$.

A design space of 400 SimSphere simulations developed using the LP-tau sampling method. In creating the input space from the 400 model runs, all SimSphere inputs were allowed to vary, except those of the geographical location (latitude/longitude) and atmospheric profile (Fig. 2), for which a priori real observations for the 7 August 2002 were used from the Loobos CarboEurope site, located in the Netherlands $\left(52^{\circ} 10^{\prime} 04.29^{\prime \prime} \mathrm{N}, 05^{\circ} 44^{\prime} 38.25^{\prime \prime} \mathrm{E}\right)$. In accordance with previous GSA studies on SimSphere, GEM-SA was implemented assuming both normal and uniform PDFs for the inputs/outputs from the model. For all variables, the theoretical 

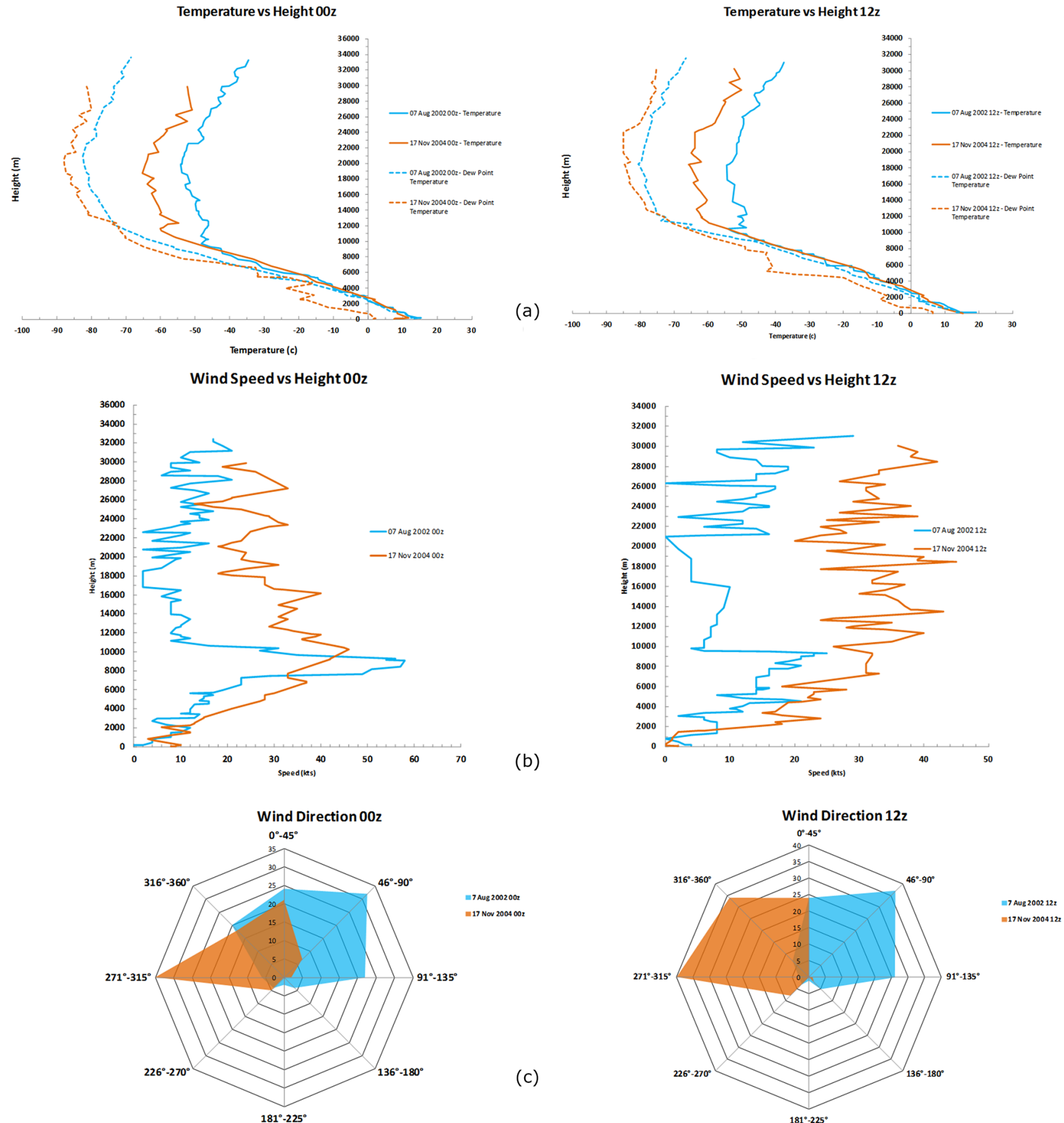

Figure 2. Atmospheric soundings used in the present study in comparison to the Petropoulos et al. (2009c) study for temperature (a, b), wind direction (c, d) and wind speed (e, f).

ranges of values were defined from the entire possible theoretical range which they could take in SimSphere parameterisation (Table 1). The potential of co-variation between the parameters was assumed negligible, as in previous studies. In addition, the emulator performance was evaluated based on the "leave final $20 \%$ out" method offered in GEM-SA, again in accordance with previous GEM-SA studies conducted to the model. 
Table 1. Summary of the SimSphere inputs considered in the GSA implementation. Units of each of the model inputs, where appropriate, are provided in brackets.

\begin{tabular}{|c|c|c|c|c|}
\hline $\begin{array}{l}\text { Model input } \\
\text { short name }\end{array}$ & $\begin{array}{l}\text { Actual name of } \\
\text { the model input }\end{array}$ & $\begin{array}{l}\text { Process in which } \\
\text { each parameter is involved }\end{array}$ & $\begin{array}{r}\text { Min } \\
\text { value }\end{array}$ & $\begin{array}{r}\text { Max } \\
\text { value }\end{array}$ \\
\hline $\mathrm{X} 1$ & Slope (degrees) & time \& location & 0 & 45 \\
\hline $\mathrm{X} 2$ & Aspect (degrees) & time \& location & 0 & 360 \\
\hline $\mathrm{X} 3$ & Station height (metres) & time \& location & 0 & 4.92 \\
\hline $\mathrm{X} 4$ & Fractional vegetation cover $(\%)$ & vegetation & 0 & 100 \\
\hline $\mathrm{X} 5$ & $\operatorname{LAI}\left(\mathrm{m}^{2} \mathrm{~m}^{-2}\right)$ & vegetation & 0 & 10 \\
\hline X6 & Foliage emissivity (unitless) & vegetation & 0.951 & 0.990 \\
\hline $\mathrm{X} 7$ & {$[\mathrm{Ca}]$ (external $\left[\mathrm{CO}_{2}\right]$ in the leaf) (ppmv) } & vegetation & 250 & 710 \\
\hline $\mathrm{X} 8$ & {$[\mathrm{Ci}]$ (internal $\left[\mathrm{CO}_{2}\right]$ in the leaf) (ppmv) } & vegetation & 110 & 400 \\
\hline X9 & [03] (ozone concentration in the air) (ppmv) & vegetation & 0.0 & 0.25 \\
\hline $\mathrm{X} 10$ & Vegetation height (metres) & vegetation & 0.021 & 20.0 \\
\hline $\mathrm{X} 11$ & Leaf width (metres) & vegetation & 0.012 & 1.0 \\
\hline $\mathrm{X} 12$ & Minimum stomatal resistance $\left(\mathrm{s} \mathrm{m}^{-1}\right)$ & plant & 10 & 500 \\
\hline $\mathrm{X} 13$ & Cuticle resistance $\left(\mathrm{s} \mathrm{m}^{-1}\right)$ & plant & 200 & 2000 \\
\hline $\mathrm{X} 14$ & Critical leaf water potential (bar) & plant & -30 & -5 \\
\hline $\mathrm{X} 15$ & Critical solar parameter $\left(\mathrm{W} \mathrm{m}^{-2}\right)$ & plant & 25 & 300 \\
\hline $\mathrm{X} 16$ & Stem resistance $\left(\mathrm{s} \mathrm{m}^{-1}\right)$ & plant & 0.011 & 0.150 \\
\hline $\mathrm{X} 17$ & Surface moisture availability (vol/vol) & hydrological & 0 & 1 \\
\hline $\mathrm{X} 18$ & Root zone moisture availability (vol/vol) & hydrological & 0 & 1 \\
\hline X19 & Substrate max volum. water content (vol/vol) & hydrological & 0.01 & 1 \\
\hline $\mathrm{X} 20$ & Substrate climatol. mean temperature $\left({ }^{\circ} \mathrm{C}\right)$ & surface & 20 & 30 \\
\hline $\mathrm{X} 21$ & Thermal inertia $\left(\mathrm{W} \mathrm{m}^{-2} \mathrm{~K}^{-1}\right)$ & surface & 3.5 & 30 \\
\hline $\mathrm{X} 22$ & Ground emissivity (unitless) & surface & 0.951 & 0.980 \\
\hline $\mathrm{X} 23$ & Atmospheric precipitable water $(\mathrm{cm})$ & meteorological & 0.05 & 5 \\
\hline $\mathrm{X} 24$ & Surface roughness (metres) & meteorological & 0.02 & 2.0 \\
\hline $\mathrm{X} 25$ & Obstacle height (metres) & meteorological & 0.02 & 2.0 \\
\hline $\mathrm{X} 26$ & Fractional cloud cover $(\%)$ & meteorological & 1 & 10 \\
\hline $\mathrm{X} 27$ & RKS (satur. thermal conduct. (Cosby et al., 1984) & soil & 0 & 10 \\
\hline $\mathrm{X} 28$ & Cosby B (see Cosby et al., 1984) & soil & 2.0 & 12.0 \\
\hline $\mathrm{X} 29$ & THM (satur. vol. water cont.) (Cosby et al., 1984) & soil & 0.3 & 0.5 \\
\hline $\mathrm{X} 30$ & PSI (satur. water potential) (Cosby et al., 1984) & soil & 1 & 7 \\
\hline
\end{tabular}

\section{Results}

\subsection{Emulator validation}

The uncertainty of the SA due to the performance of the emulator was evaluated on the basis of a number of statistical measures computed internally by GEM-SA. Those included the "cross-validation root mean square error", "crossvalidation root mean squared relative error" and the "crossvalidation root mean squared standardised error". In addition a unitless parameter called "roughness value", also computed internally in GEM-SA, was used. This parameter provides an estimate of the changes in model outputs in response to changes in the inputs to the model. Finally, the "sigmasquared" statistical parameter, also computed within GEMSA, was also used to statistically appreciate the performance of the emulator build. Within BACCO GEM-SA, this expresses the variance of the emulator after standardising the output, and effectively provides a measure of the quality of the fit of the emulator to the original model code.

Tables 2 and 3 summarise the results from the computation of the main statistical measures used to evaluate the performance of the emulator. As can be observed, sigmasquared values for all parameters were low, as were cross validation root mean square error values for all model outputs. Cross-validation root mean squared relative error varied widely between $3.03 \%$ ( $\overline{\text { Tair }_{\text {daily }}}$ ) and $41.63 \%\left(\overline{H_{\text {daily }}}\right)$. Roughness values for the majority of the model inputs were reported having very low values for both normal and uniform PDFs, indicating that the built emulator is a very good approximation of the actual model. For thermal inertia, for example, roughness values are 0 for all model outputs with the exception of $H$ flux and daily LE and $H$ fluxes (which are all 0.01 ). Most roughness values obtained were below 1.0, suggesting that the emulator responded smoothly to variations in model inputs. Roughness values above 1.0 were rare (e.g. vegetation height and surface soil moisture availability (Mo) 
for $\overline{H_{\text {daily }}}$, and aspect, fractional vegetation cover, vegetation height and Mo for $\overline{\operatorname{Trad}_{\text {daily }}}$. Noticeably, the results obtained herein in regards to the emulator accuracy were largely comparable to previous GSA studies on SimSphere (Petropoulos et al., 2009c, 2013b, c, d), suggesting a good emulator build able to emulate the target quantities examined reasonably accurately.

\subsection{SA results}

Tables 4 and 5 summarise the relative sensitivity of the model outputs with respect to its inputs, for both the cases of normal and uniform PDF assumptions for the model inputs/outputs. Input parameters with a main effect $>1 \%$ and/or $>1 \%$ total effect are highlighted in bold. Figure 3 exemplifies the main effect and total effects for each model output of which the SA was examined. The following sections systematically describe the main results obtained in terms of the SA for both cases of PDF assumption, focusing primarily on the analysis of the main and total SA indices computed.

\subsubsection{Parameter sensitivity for $\overline{\mathbf{R n}_{\text {daily }}}$}

Main effects and total effects from 0 to $50.1 \%$ and 0 to $63.6 \%$, respectively, for normal PDFs (Table 4, Fig. 3) and from 0 to $48.1 \%$ and 0 to $65.7 \%$ (Table 5), respectively, in the case of uniform PDF assumption. Under normal PDF assumption, the inputs with the largest percentage variance contribution were aspect $(50.1 \%)$, slope $(20.3 \%)$ and $\mathrm{Fr}$ (7.2\%), and LAI (2.1\%) and Mo (3.6\%) were also relevant. As Table 4 shows, these parameters also contributed significantly to the total effects, although vegetation height also contributed here $(1.2 \%)$. Clearly, changing the PDFs to uniform did not significantly alter the nature or the ranking of the most important model inputs (Table 5, Fig. 3). Yet, it is noticeable that for this PDF assumption, surface roughness input became more important, contributing $1.1 \%$ to the total effects. In summary, the model input parameters with the highest total effects (i.e. those to which $\overline{\mathrm{Rn}_{\text {daily }}}$ is most sensitive) were aspect, slope, Fr, LAI, Mo, vegetation height and surface roughness. Only nine significant $(>0.1 \%)$ first-order interactions were found for this parameter assuming a normal PDF and assuming a uniform PDF for the model inputs. Assuming a uniform PDF, the most significant first-order interactions were between slope and aspect (13.4\%) and between Fr and LAI $(0.6 \%)$. For normal PDFs the interaction between slope and aspect was by far the most important $(10.20 \%)$. Interactions between aspect and $\mathrm{Fr}(0.4 \%)$, Fr and LAI $(0.3 \%)$ and aspect and Mo $(0.3 \%)$ were also significant.

\subsubsection{Parameter sensitivity for $\overline{\boldsymbol{H}_{\text {daily }}}$}

Main effects and total effects were lower in this case and ranged from 0 to $15.2 \%$ and from 0 to $31.1 \%$, respectively, for normal PDFs (Table 4) and from 0 to $16.6 \%$ and 0 to $30.4 \%$, respectively, for uniform PDFs (Table 5). Under normal PDFs, the inputs parameters with the largest percentage variance contribution were $\operatorname{Fr}(15.2 \%)$, Mo (11.7\%), aspect $(10.9 \%)$ and vegetation height $(10.4 \%)$. Surface roughness $(3.5 \%)$ and slope $(1.4 \%)$ were also important. In terms of the total effects, aspect was the most important parameter (31.1\%) for the simulation of $\overline{H_{\text {daily }}}$ by the model, followed by vegetation height $(29.7 \%)$, Mo $(26.3 \%)$ and $\operatorname{Fr}(25.5 \%)$. A number of other parameters also showed significant total effects (Table 4). The nature and rank of significant input parameters to main effects was also not changed by changing the PDFs to uniform (Table 5, Fig. 3). In terms of the total effects, however, vegetation height becomes the most important by a small margin (30.4\% compared to $30.1 \%$ for aspect). Numerous important input parameters are seen to influence $\overline{H_{\text {daily }}}$ therefore, with the most important being aspect, Fr, vegetation height, Mo and surface roughness. A large number of first-order interactions with values higher than $0.1 \%$ were observed for $\overline{H_{\text {daily }}}$ assuming a uniform PDF (32 in total) and assuming a normal PDF (39 in total). Assuming a uniform PDF the most important interactions were between vegetation height and surface roughness $(4.76 \%)$, Fr and Mo (2.46\%), Fr and vegetation height $(1.95 \%)$, aspect and surface roughness $(1.67 \%)$ and aspect and Mo $(1.40 \%)$. The most significant interaction assuming a normal PDF was between vegetation height and surface roughness ( $4.31 \%)$, but interactions between aspect and surface roughness $(2.52 \%)$, Mo $(1.71 \%)$, vegetation height $(1.13 \%)$ and $\mathrm{O}_{3}$ in the air $(0.72 \%)$ as well as interactions between Fr and Mo $(2.26 \%)$ and vegetation height $(1.91 \%)$ were also found. In terms of second-order or higher interactions, a higher level of significant interactions was found, with 16.8 and $21.9 \%$ noted assuming normal and uniform PDFs, respectively.

\subsubsection{Parameter sensitivity for $\overline{\mathbf{L E}_{\text {daily }}}$}

As regards the $\overline{L_{\text {daily }}}$, SA results showed ranges in main effects and total effects ranging from 0 to $36.0 \%$ and 0 to $51.9 \%$, respectively, for normal PDF assumption (Table 4) and from 0 to $29.8 \%$ and 0 to $48.0 \%$, respectively, for uniform PDFs (Table 5, Fig. 3). Under normal PDFs, the model inputs with the highest percentage variance contribution were those of aspect $(36.0 \%)$, Mo (17.6\%), Fr (8.1\%), slope $(8.0 \%)$ and cuticle resistance $(1.0 \%)$. This is also mirrored in the total effects results obtained, yet at higher percentage contributions (e.g. $51.9 \%$ for the aspect). Both PSI (saturated water potential) and substrate maximum volumetric water content contributed $>1 \%$ to the total effects also. Once again, the nature and rank of significant model input parameters was mirrored when the PDFs were changed to uniform, but additional parameters contribute to the total effects, including $[\mathrm{Ca}],\left[\mathrm{O}_{3}\right]$ in the air, ground emissivity, RKS (saturated thermal conductivity), Cosby B and THM (saturated volume water content). In summary, results suggest that the most important model inputs influencing the simulation 
Table 2. Emulator accuracy statistics for the SA tests conducted in our study (under both normal and uniform PDF assumptions for the model inputs/outputs).

\begin{tabular}{|c|c|c|c|c|c|c|c|c|}
\hline Fitted model parameters (based on standardised input/output) & $\overline{\mathrm{Rn}_{\text {daily }}}$ & $\overline{H_{\text {daily }}}$ & $\overline{\mathrm{LE}_{\text {daily }}}$ & $\overline{\operatorname{Trad}_{\text {daily }}}$ & $\overline{\text { Modaily }_{\text {da }}}$ & Tair $_{\text {daily }}$ & $\overline{\mathrm{EF}_{\text {daily }}}$ & $\overline{\mathrm{NEF}_{\text {daily }}}$ \\
\hline $\begin{array}{l}\text { Sigma-squared: } \\
\text { Emulator accuracy: }\end{array}$ & 0.413 & 1.619 & 1.057 & 0.875 & 1.240 & 1.630 & 1.483 & 1.483 \\
\hline Cross-validation root mean squared error $\left(\mathrm{W} \mathrm{m}^{-2}\right)$ : & 25.060 & 34.776 & 28.798 & 2.771 & 31.012 & 0.491 & 0.082 & 0.082 \\
\hline Cross-validation root mean squared relative error $(\%)$ : & 6.349 & 41.633 & 23.485 & 7.913 & 13.814 & 3.030 & 20.033 & 25.292 \\
\hline Cross-validation root mean squared standardised error: & 1.111 & 1.790 & 1.484 & 1.117 & 1.474 & 1.505 & 1.717 & 1.717 \\
\hline
\end{tabular}

Table 3. Summarised statistics concerning the emulator accuracy evaluation for the different SimSphere model outputs examined in our study. Bold font highlights the roughness values of the model inputs with values greater than 1.0. Rows X1 to X30 show roughness values for the different model outputs examined (for normal and uniform PDFs).

\begin{tabular}{|c|c|c|c|c|c|c|c|c|}
\hline Model Inputs & $\overline{\mathrm{Rn}_{\text {daily }}}$ & $\overline{H_{\text {daily }}}$ & $\overline{\mathrm{LE}_{\text {daily }}}$ & $\overline{\operatorname{Trad}_{\text {daily }}}$ & $\overline{\text { Mo daily }}$ & $\overline{\text { Tair }_{\text {daily }}}$ & $\overline{\mathrm{EF}_{\text {daily }}}$ & $\overline{\mathrm{NEF}}_{\text {daily }}$ \\
\hline $\mathrm{X} 1$ & 1.842 & 0.092 & 0.479 & 0.755 & 0.688 & 0.488 & 0.049 & 0.049 \\
\hline $\mathrm{X} 2$ & 12.728 & 4.317 & 8.451 & 8.557 & 7.638 & 7.247 & 0.617 & 0.617 \\
\hline $\mathrm{X} 3$ & 0.156 & 0.289 & 0.105 & 0.013 & 0.611 & 0.187 & 0.043 & 0.043 \\
\hline $\mathrm{X} 4$ & 0.643 & 0.672 & 0.931 & 1.307 & 0.668 & 0.838 & 1.845 & 1.845 \\
\hline X5 & 0.608 & 0.065 & 0.062 & 0.223 & 1.027 & 0.035 & 0.150 & 0.150 \\
\hline X6 & 0.022 & 0.053 & 0.000 & 0.015 & 0.010 & 0.000 & 0.000 & 0.000 \\
\hline $\mathrm{X} 7$ & 0.001 & 0.102 & 0.094 & 0.000 & 0.012 & 0.000 & 0.091 & 0.091 \\
\hline X8 & 0.000 & 0.007 & 0.016 & 0.000 & 0.038 & 0.005 & 0.035 & 0.035 \\
\hline X9 & 0.174 & 0.172 & 0.121 & 0.338 & 0.018 & 0.201 & 0.002 & 0.002 \\
\hline X10 & 0.377 & 2.389 & 0.000 & 1.036 & 0.137 & 2.272 & 4.396 & 4.396 \\
\hline X11 & 0.019 & 0.054 & 0.040 & 0.034 & 0.156 & 0.030 & 0.030 & 0.030 \\
\hline X12 & 0.000 & 0.008 & 0.003 & 0.000 & 0.000 & 0.000 & 0.386 & 0.386 \\
\hline X13 & 0.022 & 0.048 & 0.161 & 0.043 & 0.030 & 0.040 & 0.217 & 0.217 \\
\hline X14 & 0.014 & 0.000 & 0.001 & 0.010 & 0.004 & 0.019 & 0.037 & 0.037 \\
\hline X15 & 0.016 & 0.000 & 0.000 & 0.071 & 0.000 & 0.009 & 0.000 & 0.000 \\
\hline X16 & 0.011 & 0.023 & 0.048 & 0.058 & 0.047 & 0.000 & 0.033 & 0.033 \\
\hline X17 & 1.197 & 2.146 & 1.416 & 1.048 & 0.408 & 0.422 & 1.346 & 1.346 \\
\hline X18 & 0.025 & 0.000 & 0.056 & 0.007 & 0.131 & 0.000 & 0.135 & 0.135 \\
\hline X19 & 0.000 & 0.000 & 0.077 & 0.004 & 0.048 & 0.000 & 0.070 & 0.070 \\
\hline X20 & 0.012 & 0.006 & 0.054 & 0.000 & 0.107 & 0.005 & 0.000 & 0.000 \\
\hline $\mathrm{X} 21$ & 0.005 & 0.013 & 0.000 & 0.000 & 0.000 & 0.002 & 0.011 & 0.011 \\
\hline X22 & 0.007 & 0.000 & 0.101 & 0.041 & 0.000 & 0.000 & 0.010 & 0.010 \\
\hline $\mathrm{X} 23$ & 0.004 & 0.000 & 0.042 & 0.104 & 0.055 & 0.003 & 0.098 & 0.098 \\
\hline X24 & 0.176 & 3.328 & 0.064 & 0.185 & 0.329 & 4.195 & 1.384 & 1.384 \\
\hline $\mathrm{X} 25$ & 0.030 & 0.000 & 0.053 & 0.145 & 0.169 & 0.070 & 0.000 & 0.000 \\
\hline $\mathrm{X} 26$ & 0.008 & 0.089 & 0.058 & 0.032 & 0.000 & 0.000 & 0.105 & 0.105 \\
\hline X27 & 0.000 & 0.000 & 0.092 & 0.000 & 0.026 & 0.000 & 0.000 & 0.000 \\
\hline X28 & 0.012 & 0.046 & 0.125 & 0.034 & 0.222 & 0.000 & 0.091 & 0.091 \\
\hline X29 & 0.079 & 0.178 & 0.092 & 0.102 & 0.204 & 0.026 & 0.022 & 0.022 \\
\hline X30 & 0.079 & 0.006 & 1.710 & 0.083 & 0.054 & 0.174 & 0.003 & 0.003 \\
\hline
\end{tabular}

of $\overline{\mathrm{LE}_{\text {daily }}}$ were aspect, $\mathrm{Mo}, \mathrm{Fr}$ and slope. Assuming uniform PDFs for the model inputs, two first-order interactions dominate for this parameter - those between slope and aspect once more $(6.8 \%)$ and those between Fr and Mo $(6.8 \%)$. Interactions between aspect and Mo (1.0\%) and Fr (4.6\%), respectively, are also important. When normal PDFs for model inputs/outputs were assumed, 24 first-order interactions with values higher than $0.1 \%$ were observed, and, once again, the interaction between slope and aspect $(6.1 \%)$ were the most important. However, important interactions between Fr and
Mo (4.6\%), aspect and Mo (1.2\%) and between aspect and Fr $(0.8 \%)$ were also observed.

\subsubsection{Parameter sensitivity for $\overline{\operatorname{Trad}_{\text {daily }}}$}

Main effects and total effects for $\overline{\operatorname{Trad}_{\text {daily }}}$ simulation by SimSphere ranged from 0 to $34.9 \%$ and 0 to $52.0 \%$ respectively, assuming normal PDFs for the model inputs (Table 4, Fig. 3) and from 0 to $29.6 \% 0$ to and $49.2 \%$, respectively, for the case of uniform PDFs (Table 5). For normal PDFs the most 
Table 4. Summarised results from the implementation of the BACCO GEM-SA method on the different outputs simulated by SimSphere using the normal PDFs. Computed main (ME) and total effect (TE) indices by the GEM tool (expressed as \%) for each of the model parameters are shown, whereas the last three lines summarise the percentages of the explained total output variance of the main effects alone and after including the interaction effects. Input parameters with a variance decomposition of greater than $1 \%$ are highlighted in bold font.

\begin{tabular}{|c|c|c|c|c|c|c|c|c|c|c|c|c|c|c|c|c|}
\hline \multirow[t]{2}{*}{ Model Input } & \multicolumn{2}{|c|}{$\overline{\mathrm{Rn}_{\text {daily }}}$} & \multicolumn{2}{|c|}{$\overline{H_{\text {daily }}}$} & \multicolumn{2}{|c|}{$\overline{\mathrm{LE}_{\text {daily }}}$} & \multicolumn{2}{|c|}{$\overline{\operatorname{Trad}_{\text {daily }}}$} & \multicolumn{2}{|c|}{$\overline{\text { Modaily }}$} & \multicolumn{2}{|c|}{$\overline{\text { Tair }_{\text {daily }}}$} & \multicolumn{2}{|c|}{$\overline{\mathrm{EF}_{\text {daily }}}$} & \multicolumn{2}{|c|}{$\overline{\mathrm{NEF}_{\text {daily }}}$} \\
\hline & ME & $\mathrm{TE}$ & ME & TE & ME & $\mathrm{TE}$ & ME & TE & ME & TE & ME & $\mathrm{TE}$ & ME & $\mathrm{TE}$ & ME & TE \\
\hline $\mathrm{X} 1$ & 20.294 & 31.964 & 1.388 & 3.078 & 7.969 & 16.245 & 12.676 & 24.032 & 17.129 & 29.450 & 1.846 & 10.150 & 0.991 & 1.613 & 0.991 & 1.613 \\
\hline $\mathrm{X} 2$ & 50.095 & 63.626 & 10.944 & 31.147 & 36.024 & 51.870 & 34.857 & 52.048 & 28.462 & 50.207 & 21.877 & 43.797 & 4.283 & 8.883 & 4.283 & 8.882 \\
\hline $\mathrm{X} 3$ & 0.016 & 0.353 & 0.469 & 4.245 & 0.066 & 0.825 & 0.031 & 0.150 & 1.278 & 4.853 & 0.411 & 2.482 & 0.130 & 0.610 & 0.130 & 0.610 \\
\hline $\mathrm{X} 4$ & 7.161 & 8.916 & 15.239 & 25.509 & 8.132 & 16.975 & 5.586 & 10.606 & 0.704 & 6.702 & 16.655 & 25.647 & 10.362 & 26.932 & 10.362 & 26.932 \\
\hline X5 & 2.060 & 3.357 & 0.135 & 1.710 & 0.184 & 0.709 & 0.049 & 1.462 & 12.028 & 20.080 & 0.071 & 0.672 & 0.060 & 1.824 & 0.060 & 1.824 \\
\hline X6 & 0.014 & 0.094 & 0.142 & 1.136 & 0.027 & 0.028 & 0.048 & 0.177 & 0.030 & 0.151 & 0.020 & 0.022 & 0.032 & 0.034 & 0.032 & 0.034 \\
\hline X7 & 0.010 & 0.015 & 0.090 & 2.166 & 0.049 & 0.855 & 0.028 & 0.029 & 0.054 & 0.198 & 0.037 & 0.039 & 0.065 & 1.086 & 0.065 & 1.086 \\
\hline $\mathrm{X} 8$ & 0.008 & 0.008 & 0.120 & 0.262 & 0.031 & 0.181 & 0.020 & 0.021 & 0.065 & 0.474 & 0.102 & 0.200 & 0.060 & 0.544 & 0.060 & 0.544 \\
\hline $\mathrm{X} 9$ & 0.029 & 0.465 & 0.093 & 3.309 & 0.098 & 0.898 & 0.149 & 1.703 & 0.032 & 0.222 & 0.067 & 2.669 & 0.093 & 0.120 & 0.093 & 0.120 \\
\hline $\mathrm{X} 10$ & 0.427 & 1.234 & 10.357 & 29.664 & 0.015 & 0.016 & 3.293 & 7.415 & 0.803 & 2.066 & 7.832 & 22.447 & 8.155 & 24.214 & 8.155 & 24.214 \\
\hline X11 & 0.021 & 0.095 & 0.275 & 1.401 & 0.350 & 0.677 & 0.127 & 0.432 & 0.177 & 2.093 & 0.044 & 0.500 & 0.308 & 0.759 & 0.308 & 0.759 \\
\hline $\mathrm{X} 12$ & 0.006 & 0.007 & 0.137 & 0.306 & 0.065 & 0.091 & 0.026 & 0.027 & 0.033 & 0.034 & 0.058 & 0.060 & 0.442 & 3.400 & 0.442 & 3.400 \\
\hline X13 & 0.134 & 0.203 & 0.158 & 1.041 & 1.546 & 2.699 & 0.609 & 0.922 & 0.151 & 0.490 & 0.247 & 0.929 & 1.652 & 4.295 & 1.653 & 4.295 \\
\hline X14 & 0.013 & 0.066 & 0.088 & 0.090 & 0.037 & 0.052 & 0.074 & 0.155 & 0.131 & 0.174 & 0.097 & 0.395 & 0.155 & 0.599 & 0.155 & 0.599 \\
\hline X15 & 0.024 & 0.077 & 0.037 & 0.039 & 0.041 & 0.042 & 0.070 & 0.506 & 0.030 & 0.031 & 0.122 & 0.260 & 0.025 & 0.026 & 0.025 & 0.026 \\
\hline X16 & 0.021 & 0.057 & 0.242 & 0.717 & 0.021 & 0.422 & 0.168 & 0.563 & 0.042 & 0.648 & 0.055 & 0.057 & 0.042 & 0.477 & 0.042 & 0.477 \\
\hline X17 & 3.554 & 5.219 & 11.669 & 26.284 & 17.567 & 27.166 & 16.911 & 21.465 & 3.563 & 7.129 & 7.010 & 11.169 & 38.200 & 49.518 & 38.199 & 49.518 \\
\hline X18 & 0.071 & 0.160 & 0.099 & 0.101 & 0.251 & 0.707 & 0.095 & 0.159 & 0.054 & 1.229 & 0.143 & 0.145 & 0.835 & 2.507 & 0.835 & 2.507 \\
\hline X19 & 0.010 & 0.010 & 0.054 & 0.056 & 0.643 & 1.300 & 0.056 & 0.090 & 0.284 & 0.735 & 0.033 & 0.035 & 0.286 & 1.055 & 0.286 & 1.056 \\
\hline $\mathrm{X} 20$ & 0.083 & 0.125 & 0.190 & 0.308 & 0.098 & 0.538 & 0.346 & 0.347 & 0.749 & 1.608 & 0.167 & 0.256 & 0.036 & 0.038 & 0.036 & 0.038 \\
\hline $\mathrm{X} 21$ & 0.032 & 0.050 & 0.228 & 0.487 & 0.029 & 0.030 & 0.043 & 0.044 & 0.035 & 0.037 & 0.105 & 0.137 & 0.072 & 0.234 & 0.072 & 0.234 \\
\hline $\mathrm{X} 22$ & 0.016 & 0.043 & 0.119 & 0.121 & 0.130 & 0.841 & 0.043 & 0.449 & 0.055 & 0.057 & 0.094 & 0.096 & 0.045 & 0.194 & 0.045 & 0.194 \\
\hline $\mathrm{X} 23$ & 0.009 & 0.025 & 0.052 & 0.054 & 0.032 & 0.378 & 0.042 & 0.718 & 0.124 & 0.653 & 0.025 & 0.081 & 0.066 & 1.239 & 0.066 & 1.239 \\
\hline $\mathrm{X} 24$ & 0.285 & 0.745 & 3.509 & 24.425 & 0.222 & 0.707 & 0.853 & 2.332 & 1.391 & 4.019 & 6.465 & 23.644 & 1.318 & 9.913 & 1.318 & 9.913 \\
\hline $\mathrm{X} 25$ & 0.010 & 0.129 & 0.049 & 0.051 & 0.044 & 0.552 & 0.051 & 1.067 & 0.061 & 1.551 & 0.042 & 1.070 & 0.075 & 0.076 & 0.075 & 0.076 \\
\hline $\mathrm{X} 26$ & 0.030 & 0.059 & 0.264 & 2.020 & 0.079 & 0.625 & 0.087 & 0.368 & 0.051 & 0.052 & 0.047 & 0.049 & 0.050 & 1.240 & 0.050 & 1.240 \\
\hline X27 & 0.005 & 0.005 & 0.043 & 0.045 & 0.032 & 0.909 & 0.017 & 0.018 & 0.053 & 0.330 & 0.031 & 0.033 & 0.026 & 0.028 & 0.026 & 0.028 \\
\hline X28 & 0.035 & 0.075 & 0.072 & 1.019 & 0.044 & 0.882 & 0.049 & 0.321 & 0.374 & 2.540 & 0.082 & 0.084 & 0.224 & 1.261 & 0.224 & 1.261 \\
\hline X29 & 0.058 & 0.289 & 0.402 & 2.995 & 0.028 & 0.866 & 0.344 & 1.024 & 0.103 & 2.105 & 0.206 & 0.585 & 0.118 & 0.404 & 0.118 & 0.404 \\
\hline X30 & 0.036 & 0.276 & 0.074 & 0.199 & 0.285 & 5.121 & 0.096 & 0.781 & 0.042 & 0.661 & 0.071 & 2.333 & 0.052 & 0.099 & 0.052 & 0.099 \\
\hline Main effects only & 84.568 & & 56.735 & & 74.138 & & 76.844 & & 68.091 & & 64.061 & & 68.258 & & 68.258 & \\
\hline $\begin{array}{l}1 \text { st-order } \\
\text { interactions only }\end{array}$ & 13.486 & & 26.454 & & 19.706 & & 17.916 & & 24.610 & & 24.309 & & 22.129 & & 22.129 & \\
\hline $\begin{array}{l}\text { 2nd- or higher- } \\
\text { order interactions }\end{array}$ & 1.946 & & 16.810 & & 6.155 & & 5.240 & & 7.299 & & 11.630 & & 9.613 & & 9.613 & \\
\hline
\end{tabular}

important model inputs were aspect (34.9\%), Mo (16.9\%) and slope $(12.7 \%)$, with Fr and vegetation height also important. This is mirrored in the total effects, but here LAI, $\left[\mathrm{O}_{3}\right]$ in the air, surface roughness, obstacle height and THM also contributed more than $1 \%$. The nature and ranking of the model inputs contributing significant main effects under uniform PDFs were largely similar to those of normal PDFs. In common with the parameters discussed above, therefore, aspect, slope, Mo and vegetation characteristics (Fr and height) exert the most influence on $\overline{\operatorname{Trad}_{\text {daily }}}$. Assuming a uniform PDF, 21 first-order interactions with values higher than $0.1 \%$ were reported. The most important was between slope and aspect $(9.5 \%)$, followed by some less important interactions, e.g. between Fr and Mo (1.2\%) and between aspect and Mo $(0.8 \%)$. Assuming a normal PDF 24 significant firstorder interactions with values higher than $0.1 \%$ were returned. The two most important were once again between slope and aspect $(8.9 \%)$ and between aspect and Mo $(0.9 \%)$. Interactions between Fr and Mo $(0.9 \%)$ and aspect and Fr $(0.7 \%)$ were also important. Second-order or higher interactions contributed 5.2 and $8.0 \%$ in the total variance decomposition for the normal and uniform PDFs, respectively.

\subsubsection{Parameter sensitivity for $\overline{\text { Modaily }_{\text {da }}}$}

For main and total effects for normal PDFs, a similar range was observed for $\overline{\mathrm{Mo}_{\text {daily }}}$ to those of other parameters, from 0 to $28.5 \%$ and 0 to $50.2 \%$, respectively (Table 4, Fig. 3). However, a much larger range was observed for these values under uniform PDFs - from 0 to $96.4 \%$ and 0 to $97.6 \%$ for main and total effects, respectively (Table 5). For normal PDFs the most important model input parameters were aspect $(28.5 \%)$, slope $(17.1 \%)$ and LAI $(12.0 \%)$ in the main effects. These were also important in terms of total effects, but in addition many other factors also become important in that case, the most significant being Mo (7.1\%), Fr $(6.7 \%)$ and station height $(4.9 \%)$. In this case therefore, although the most significant parameters were, once again, aspect and slope, many other parameters also appear to contribute to the sensitivity of $\overline{\mathrm{Mo}_{\text {daily }}}$. Evidently, a marked difference in terms of sensitivity was observed when a uniform PDF is assumed for this parameter (Table 5, Fig. 3). In this case, the sensitivity is dominated by Mo in both the main and total effects - 96.4 and $97.6 \%$, respectively. In the total effects, substrate maximum volumetric water content and PSI both contributed to a much lesser degree. For the case of uniform PDFs, 
Table 5. Summarised results from the implementation of the BACCO GEM-SA method on the different outputs simulated by SimSphere using the uniform PDFs. Computed main (ME) and total effect (TE) indices by the GEM tool (expressed as \%) for each of the model parameters are shown, whereas the last three lines summarise the percentages of the explained total output variance of the main effects alone and after including the interaction effects. Input parameters with a variance decomposition of greater than $1 \%$ are highlighted in bold font.

\begin{tabular}{|c|c|c|c|c|c|c|c|c|c|c|c|c|c|c|c|c|}
\hline \multirow{2}{*}{$\begin{array}{l}\text { Model Input } \\
\text { X1 }\end{array}$} & \multicolumn{2}{|c|}{$\overline{\mathrm{Rn}_{\text {daily }}}$} & \multicolumn{2}{|c|}{$\overline{H_{\text {daily }}}$} & \multicolumn{2}{|c|}{$\overline{\mathrm{LE}_{\text {daily }}}$} & \multicolumn{2}{|c|}{$\overline{\text { Trad }_{\text {daily }}}$} & \multicolumn{2}{|c|}{$\overline{\mathrm{Mo}_{\text {daily }}}$} & \multicolumn{2}{|c|}{$\overline{\text { Tair }_{\text {daily }}}$} & \multicolumn{2}{|c|}{$\overline{\mathrm{EF}_{\text {daily }}}$} & \multicolumn{2}{|c|}{$\overline{\mathrm{NEF}_{\text {daily }}}$} \\
\hline & ME & TE & ME & TE & ME & TE & ME & TE & ME & TE & ME & TE & ME & TE & ME & TE \\
\hline $\mathrm{X} 2$ & 12.975 & 28.482 & 1.275 & 3.143 & 4.924 & 14.568 & 8.652 & 21.467 & 0.004 & 0.137 & 1.629 & 11.437 & 1.060 & 1.835 & 1.060 & 1.836 \\
\hline $\mathrm{X} 3$ & 48.063 & 65.740 & 8.488 & 30.090 & 29.778 & 48.045 & 29.559 & 49.160 & 0.030 & 0.225 & 18.069 & 43.831 & 2.378 & 7.725 & 2.378 & 7.725 \\
\hline $\mathrm{X} 4$ & 0.011 & 0.486 & 0.493 & 4.965 & 0.062 & 1.103 & 0.054 & 0.207 & 0.005 & 0.064 & 0.227 & 3.012 & 0.126 & 0.747 & 0.126 & 0.747 \\
\hline X5 & 9.495 & 12.012 & 16.600 & 28.455 & 8.924 & 21.070 & 5.572 & 12.051 & 0.069 & 0.106 & 16.940 & 28.347 & 9.465 & 30.328 & 9.465 & 30.328 \\
\hline X6 & 2.588 & 4.589 & 0.190 & 1.926 & 0.255 & 0.920 & 0.046 & 2.046 & 0.002 & 0.002 & 0.073 & 0.835 & 0.043 & 2.241 & 0.043 & 2.241 \\
\hline $\mathrm{X} 7$ & 0.010 & 0.121 & 0.122 & 1.265 & 0.030 & 0.031 & 0.044 & 0.210 & 0.004 & 0.004 & 0.023 & 0.025 & 0.035 & 0.037 & 0.035 & 0.037 \\
\hline X8 & 0.013 & 0.020 & 0.078 & 2.519 & 0.044 & 1.150 & 0.032 & 0.033 & 0.004 & 0.019 & 0.042 & 0.044 & 0.043 & 1.353 & 0.043 & 1.353 \\
\hline X9 & 0.010 & 0.010 & 0.096 & 0.253 & 0.042 & 0.234 & 0.023 & 0.025 & 0.006 & 0.093 & 0.098 & 0.218 & 0.045 & 0.653 & 0.045 & 0.653 \\
\hline $\mathrm{X} 10$ & 0.035 & 0.646 & 0.148 & 3.845 & 0.072 & 1.130 & 0.140 & 2.224 & 0.001 & 0.020 & 0.165 & 3.944 & 0.100 & 0.134 & 0.100 & 0.134 \\
\hline X11 & 0.459 & 1.614 & 8.144 & 30.406 & 0.017 & 0.018 & 2.941 & 8.203 & 0.002 & 0.003 & 5.886 & 23.266 & 7.743 & 27.736 & 7.743 & 27.737 \\
\hline $\mathrm{X} 12$ & 0.041 & 0.140 & 0.325 & 1.595 & 0.342 & 0.765 & 0.209 & 0.603 & 0.003 & 0.032 & 0.046 & 0.651 & 0.287 & 0.857 & 0.287 & 0.857 \\
\hline $\mathrm{X} 13$ & 0.008 & 0.008 & 0.150 & 0.341 & 0.072 & 0.104 & 0.030 & 0.031 & 0.003 & 0.003 & 0.065 & 0.068 & 0.341 & 4.153 & 0.341 & 4.153 \\
\hline X14 & 0.179 & 0.277 & 0.249 & 1.234 & 1.791 & 3.330 & 0.689 & 1.110 & 0.014 & 0.038 & 0.418 & 1.263 & 1.885 & 5.225 & 1.885 & 5.225 \\
\hline $\mathrm{X} 15$ & 0.014 & 0.088 & 0.087 & 0.089 & 0.041 & 0.060 & 0.085 & 0.191 & 0.005 & 0.022 & 0.105 & 0.496 & 0.135 & 0.699 & 0.135 & 0.699 \\
\hline X16 & 0.035 & 0.111 & 0.037 & 0.039 & 0.046 & 0.047 & 0.077 & 0.682 & 0.003 & 0.003 & 0.149 & 0.326 & 0.027 & 0.029 & 0.027 & 0.029 \\
\hline $\mathrm{X} 17$ & 0.026 & 0.076 & 0.280 & 0.811 & 0.023 & 0.536 & 0.172 & 0.699 & 0.002 & 0.002 & 0.062 & 0.065 & 0.060 & 0.620 & 0.060 & 0.620 \\
\hline $\mathrm{X} 18$ & 4.907 & 7.116 & 11.788 & 28.159 & 20.154 & 33.046 & 22.206 & 28.072 & 96.361 & 97.557 & 8.174 & 13.430 & 35.735 & 49.092 & 35.735 & 49.092 \\
\hline X19 & 0.073 & 0.196 & 0.098 & 0.100 & 0.321 & 0.921 & 0.112 & 0.195 & 0.346 & 0.472 & 0.162 & 0.164 & 0.635 & 2.692 & 0.635 & 2.692 \\
\hline $\mathrm{X} 20$ & 0.012 & 0.013 & 0.053 & 0.055 & 0.708 & 1.564 & 0.061 & 0.105 & 0.950 & 2.090 & 0.037 & 0.039 & 0.297 & 1.262 & 0.297 & 1.262 \\
\hline $\mathrm{X} 21$ & 0.092 & 0.151 & 0.188 & 0.319 & 0.117 & 0.693 & 0.396 & 0.398 & 0.001 & 0.002 & 0.181 & 0.294 & 0.039 & 0.041 & 0.039 & 0.041 \\
\hline $\mathrm{X} 22$ & 0.038 & 0.062 & 0.192 & 0.480 & 0.032 & 0.034 & 0.049 & 0.051 & 0.002 & 0.009 & 0.116 & 0.156 & 0.079 & 0.280 & 0.079 & 0.280 \\
\hline $\mathrm{X} 23$ & 0.027 & 0.065 & 0.117 & 0.120 & 0.120 & 1.052 & 0.026 & 0.532 & 0.002 & 0.002 & 0.106 & 0.108 & 0.048 & 0.233 & 0.048 & 0.233 \\
\hline $\mathrm{X} 24$ & 0.011 & 0.034 & 0.051 & 0.054 & 0.036 & 0.495 & 0.048 & 0.955 & 0.003 & 0.003 & 0.028 & 0.099 & 0.071 & 1.620 & 0.071 & 1.620 \\
\hline $\mathrm{X} 25$ & 0.405 & 1.081 & 3.761 & 27.617 & 0.281 & 0.913 & 1.136 & 3.181 & 0.006 & 0.015 & 4.772 & 26.161 & 1.217 & 12.448 & 1.217 & 12.448 \\
\hline $\mathrm{X} 26$ & 0.009 & 0.184 & 0.049 & 0.051 & 0.031 & 0.687 & 0.041 & 1.452 & 0.009 & 0.019 & 0.080 & 1.392 & 0.081 & 0.083 & 0.081 & 0.083 \\
\hline $\mathrm{X} 27$ & 0.031 & 0.073 & 0.250 & 2.123 & 0.079 & 0.774 & 0.067 & 0.429 & 0.004 & 0.004 & 0.053 & 0.055 & 0.041 & 1.584 & 0.041 & 1.584 \\
\hline $\mathrm{X} 28$ & 0.006 & 0.007 & 0.042 & 0.045 & 0.041 & 1.128 & 0.020 & 0.021 & 0.015 & 0.454 & 0.035 & 0.037 & 0.028 & 0.030 & 0.028 & 0.030 \\
\hline X29 & 0.049 & 0.106 & 0.082 & 1.130 & 0.040 & 1.145 & 0.091 & 0.446 & 0.058 & 0.797 & 0.093 & 0.095 & 0.373 & 1.682 & 0.372 & 1.682 \\
\hline \multirow[t]{2}{*}{ X30 } & 0.092 & 0.436 & 0.470 & 3.459 & 0.090 & 1.130 & 0.488 & 1.384 & 0.010 & 0.417 & 0.201 & 0.687 & 0.115 & 0.480 & 0.115 & 0.480 \\
\hline & 0.022 & 0.361 & 0.082 & 0.220 & 0.137 & 6.415 & 0.046 & 0.956 & 0.026 & 1.103 & 0.060 & 3.286 & 0.055 & 0.113 & 0.055 & 0.113 \\
\hline Main effects Only & 79.736 & & 53.985 & & 68.651 & & 73.112 & & 97.950 & & 58.096 & & 62.586 & & 62.586 & \\
\hline $\begin{array}{l}1 \text { st-order } \\
\text { interactions only }\end{array}$ & 17.077 & & 24.146 & & 22.103 & & 18.889 & & 0.830 & & 24.932 & & 22.731 & & 22.731 & \\
\hline $\begin{array}{l}\text { 2nd- or higher- } \\
\text { order interactions }\end{array}$ & 3.187 & & 21.869 & & 9.246 & & 7.999 & & 1.220 & & 16.972 & & 14.683 & & 14.683 & \\
\hline
\end{tabular}

only one first-order interaction with values higher than $0.1 \%$ was observed between Mo and substrate maximum volumetric water content $(0.2 \%)$. Thirty-two first-order interactions with values higher than $0.1 \%$ were reported assuming a normal PDF for the model inputs/outputs. The interaction between slope and aspect was once again the most significant $(8.5 \%)$, followed by that between Fr and LAI $(2.18 \%)$. Interactions between aspect and LAI (1.4\%) and Mo $(1.2 \%)$, respectively, were also important.

\subsubsection{Parameter sensitivity for $\overline{\text { Tair }_{\text {daily }}}$}

Ranges of main and total effects for this parameter were found to be comparable to the majority of the other parameters discussed previously. For normal PDFs these range from 0 to $21.89 \%$ and from 0 to $43.8 \%$, respectively (Table 4, Fig. 3), and for uniform PDFs these range from 0 to $18.1 \%$ and 0 to $43.8 \%$ (Table 5), respectively. For main effects under normal PDFs the most significant model input parameters were, once again, aspect $(21.9 \%)$, Fr (16.7\%), vegetation height $(7.8 \%)$, surface Mo $(7.0 \%)$ and surface roughness $(6.5 \%)$. The total effects were broadly similar, but surface roughness became the third-most-important parameter, whereas other inputs (e.g. station height, $\left[\mathrm{O}_{3}\right]$ in the air, obstacle height and PSI) become important. Under uniform PDFs, the most important parameters were aspect $(18.1 \%)$, Fr $(16.9 \%)$, Mo $(8.2 \%)$, vegetation height $(5.9 \%)$ and surface roughness $(4.8 \%)$. Under total effects, once again, surface roughness becomes more important, and the same additional model parameters as were observed under normal PDFs also contributed greater than $1 \%$. Once again, aspect, Fr, vegetation height and surface roughness seem to be the most important variables influencing $\overline{\text { Tair }_{\text {daily }}}$.

Twenty-three first-order interactions with values higher than $0.1 \%$ were found for this parameter, and, once again, the interaction between slope and aspect is the most important $(5.2 \%)$, although it is closely followed by interactions between vegetation height and surface roughness ( $4.4 \%)$, between Fr and vegetation height $(2.0 \%)$ and between aspect and surface roughness $(1.9 \%)$. Of the 23 first-order interactions higher than $0.1 \%$ also found assuming a normal PDF for model inputs/outputs, the most important was between slope and aspect $(5.0 \%)$, closely followed by the interactions between vegetation height and surface roughness $(4.1 \%)$ inputs, but a number of other important interactions are 

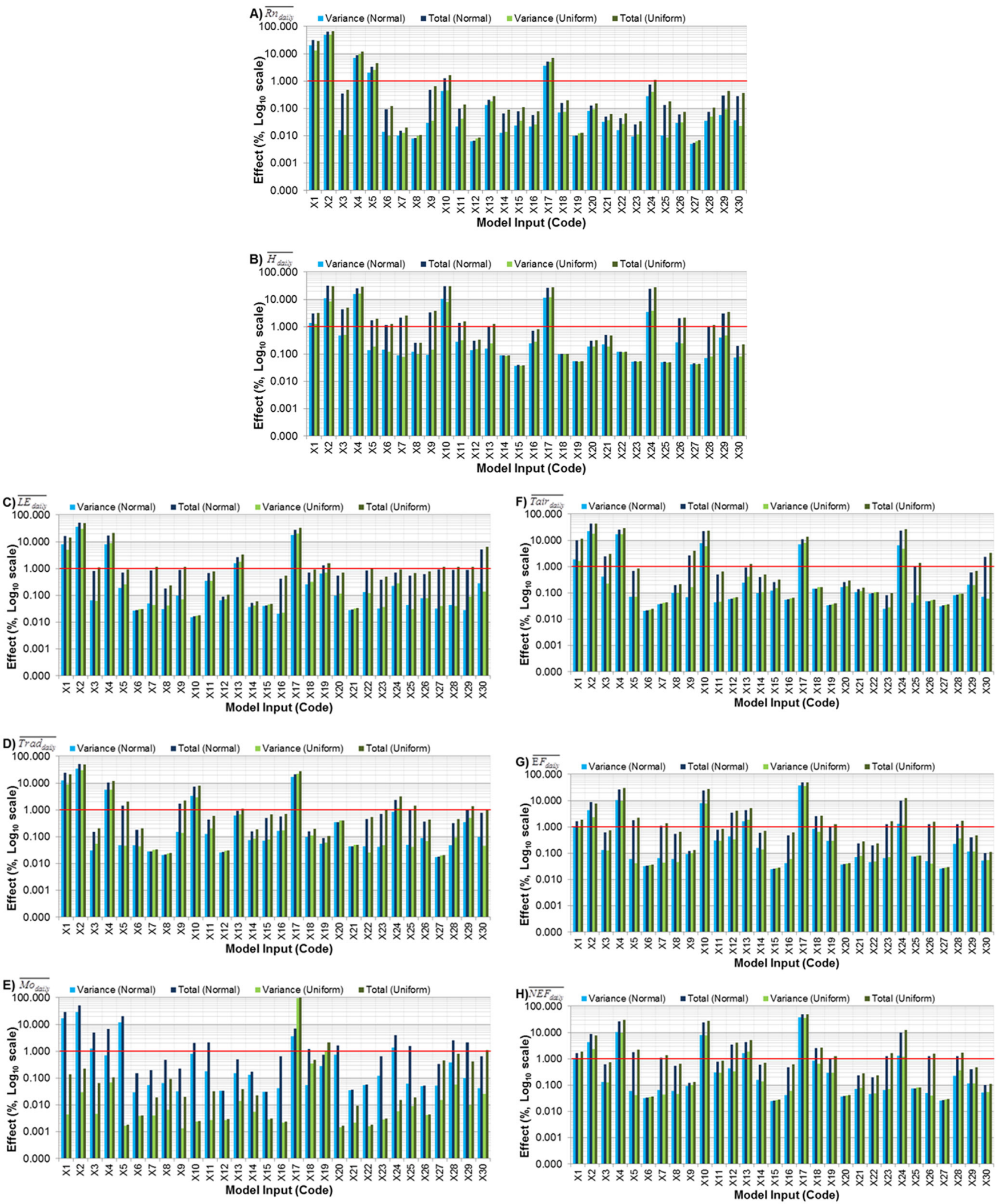

Figure 3. Variance decomposition and total effects of the model inputs examined for (A) $\overline{\mathrm{Rn}_{\text {daily }}},(\mathbf{B}) \overline{H_{\text {daily }}},(\mathbf{C}) \overline{\mathrm{LE}_{\text {daily }}}$, (D) $\overline{\operatorname{Trad}_{\text {daily }}}$, (E) $\overline{\mathrm{Mo}_{\text {daily }}},(\mathbf{F}) \overline{T_{\text {air }}}$ daily,$(\mathbf{G}) \overline{\mathrm{EF}_{\text {daily }}}$ and $(\mathbf{H}) \overline{\mathrm{NEF}_{\text {daily }}}$. Vertical axis is logarithmic $\left(\log _{10}\right)$, with the horizontal red line at $1 \%$ signifying those parameters that are highlighted in Tables 3 and 4. The definitions of the parameters in $x$ axes have been provided in Table 1. 
evident. These include interactions between aspect and surface roughness $(2.3 \%)$, vegetation height $(1.5 \%)$, Fr $(1.4 \%)$ and Mo $(0.7 \%)$, as well as between Fr and vegetation height $(1.9 \%)$ and surface roughness $(1.0 \%)$.

\subsubsection{Parameter sensitivity for $\overline{\mathbf{E F}_{\text {daily }}}$}

Once again, the ranges of main and total effects reported for the sensitivity of $\overline{\mathrm{EF}_{\text {daily }}}$ were to a large degree similar to most of the other parameters already discussed. For normal PDFs, main and total effects of the inputs ranged widely from 0 to $38.2 \%$ and from 0 to $49.5 \%$, respectively (Table 4, Fig. 3), and for the case of uniform PDFs from 0 to $35.7 \%$ and from 0 to $49.1 \%$, respectively (Table 5). Mo was found to be the most important model input parameter here in terms of main effects under normal PDFs (38.2\%), followed by Fr (10.4\%), vegetation height (8.2\%) and aspect $(4.3 \%)$. As Table 4 shows, many additional parameters become important contributors to total effects although the nature and rank of the most significant parameters does not change. Once again, Table 5 shows very little differences in terms of the nature and ranking of the main and total effects under a uniform PDF assumption for the model inputs/outputs. Therefore, for this parameter simulation in SimSphere, the most important model input parameters are Mo, Fr, vegetation height and aspect. Assuming a uniform PDF, 32 firstorder interactions with values higher than $0.1 \%$ were observed for this parameter, with the most important being between Fr and Mo (5.4\%) and vegetation height (4.2\%), respectively, and between vegetation height and surface roughness $(1.9 \%)$. Thirty-one first-order interactions with values higher than $0.1 \%$ were found assuming normal PDFs. The two most important are those between Fr and Mo $(4.8 \%)$ and vegetation height $(3.7 \%)$. Other important interactions included those between vegetation height and surface roughness $(1.9 \%)$ and Mo $(0.8 \%)$, and between Fr and cuticle resistance $(0.7 \%)$. Second- or higher-order interactions for this parameter assuming normal PDFs were largely similar to those observed for other parameters.

\subsubsection{Parameter sensitivity for $\overline{\mathbf{N E F}_{\text {daily }}}$}

The main and total effects for this parameter assuming both normal (Table 4, Fig. 3) and uniform PDFs (Table 5) were very similar (if not identical) to those observed for $\overline{\mathrm{LE}_{\text {daily }}}$. The first-order interactions with values higher than $0.1 \%$ for this parameter were very similar to those for $\overline{\mathrm{EF}_{\text {daily }}}$ with respect to the nature and ranking of the most important interactions assuming both normal and uniform PDFs, as were the contributions of second-order or higher interactions.

\section{Discussion}

The aim of this study was to undertake a SA on the SimSphere SVAT model using different atmospheric sounding data from another location compared to previous SA studies on the model, in order to identify whether this had any impact on the model sensitivity to a set of input parameters. The most important implication of this study is that the same input parameters (in broadly the same ranking of importance) have been identified as the most significant influences on model outputs despite the SA using sounding data from a different site, in a different region and under a different climatic regime. The fact that this has not shown any major differences in the nature of the model sensitivity, especially the ranking of importance, is a significant step forward in terms of the model use, in that it demonstrates the applicability of the model at different sites. It has also shown that - although the complex combinations of slope, aspect, vegetation and soil characteristics that are unique to each site will introduce some site-specific results (Ellis and Pomeroy, 1975) - in broad terms the most important parameters governing the sensitivity of model outputs do not change. This further confirms the findings of Petropoulos et al. (2013b, c) that, by fixing the relatively unimportant model inputs to typical value ranges, the dimensionality of SimSphere could be reduced and its robustness could thus be further improved. The fact that a large number of significant first-order interactions have been found for almost all the model outputs, as well as substantial contributions of higher-order interactions, is important since it further confirms that the model is coherent. This also suggests that no parts of the model are redundant and that there is no need to remove any element of the model architecture.

In common with the other recent SA experiments undertaken on SimSphere (e.g. Petropoulos et al., 2009c, 2013b, c, d), this study has shown that slope and aspect are the two most significant input parameters in terms of their influence on the model outputs, even assuming different PDFs. As has been outlined in these previous works, the influence of these topographic parameters is a result of their control on the amount of incoming solar radiation reaching the surface of the Earth (Oliphant et al., 2003; Sabetraftar et al., 2011). As a result they will also influence LE and $H$ fluxes surface temperature by providing energy for evapotranspiration and heat transfer through the surface energy budget. High levels of incoming solar radiation can be translated into high sensible heat transfers and into high surface temperatures. First-order interactions between slope and aspect that were higher than all other first-order interactions for numerous model outputs further demonstrate the sensitivity of the model outputs to these parameters.

Once again, in common with other SAs undertaken on the model, vegetation parameters have been shown to be important, and the reasons for this discussed at length previously by Petropoulos et al. (2009c, 2013b, c). In summary, both Fr and vegetation height may influence the surface energy budget by influencing the proportion of incoming solar radiation that reaches the surface of the Earth. Large Fr shades the Earth surface and, as such, will influence sur- 
face temperatures. The proportion of vegetation can affect the fluxes of both LE and $H$ fluxes through its influence on evapotranspiration, for example, as well as the proportion of incoming solar radiation which is reflected and emitted by the surface. By reducing wind speed and evaporation and increasing plant transpiration, vegetation height and surface roughness can influence surface temperatures as well as the proportion of incoming solar radiation that is converted into latent or sensible heat. The influence of Mo on $\overline{\mathrm{LE}_{\text {daily }}}$ is to be expected, as is its influence on LE fluxes. Previous SA works on SimSphere have shown that Mo can influence air temperature (Carlson and Boland, 1978; Petropoulos et al., 2009c, 2013c) because it can exert a significant control on evapotranspiration (Santanello et al., 2009; Dirmeyer, 2011; Lockart et al., 2012) and, therefore, the partitioning of net radiation into LE and $H$ fluxes. The importance of Fr is important since it is one of the two parameters in the triangle method, and its more recent modifications (Chauhan et al., 2003) for deriving LE and $H$ fluxes as well as SMC from EO data (Petropoulos et al., 2009c) and this work have shown once again that this method correctly identifies Fr and Mo as important variables.

The results of this study have significant implications for the development of successful modelling approaches involving the use of SimSphere either as a standalone application or synergistically with EO data. These results evidently further confirm the model coherence and solid structure in estimating land surface interactions, supporting ongoing work with the model on a global scale. Results obtained herein can be used practically to assist in future model parameterisation and implementation in diverse ecosystem conditions, allowing better understanding of Earth system and feedback processes. In particular the synergistic use of SimSphere with EO data via the triangle method appears to be a promising direction in this respect in providing regional estimates of key parameters characterising land surface interactions at different observational scales exploiting EO technology.

\section{Conclusions}

This study represents a significant step forward in the validation of the coherence of the SimSphere SVAT model, an effort currently ongoing globally. Whereas previous work has examined the influence of different parameters and PDFs against real observations collected from a site in Italy, this study examines the sensitivity of the model against data collected from a different region with a different climatic regime. In common with previous works, results confirmed that, once again, model outputs are only significantly sensitive to a small group of model inputs. Slope and aspect were the most important, but the influence of vegetation parameters (vegetation height, Fr and surface roughness) and soil moisture content are also important influences on a number of output parameters. Significant interactions have also been found to exist between the input parameters. The latter suggests that the model is a coherent representation of realworld processes and that natural feedbacks and interactions between, for example, vegetation and soil moisture are being represented.

In common with previous SA on SimSphere, this study has examined runs of the model at 11 a.m. UTC. Examining the sensitivity of the model outputs at different times would be a very important direction in which future SA studies on SimSphere could be conducted. In combination with direct comparisons of the model outputs against in situ "reference" estimates diurnally, conducted at different ecosystem and environmental conditions, this can assist to further extend our understanding of the SimSphere structure and establish further its coherence and correspondence to the behaviour of natural systems. It will also provide information that will be of key scientific and practical value as regards the model use, particularly as the use of SimSphere is at present expanding globally.

Acknowledgements. G. P. Petropoulos gratefully acknowledges the financial support provided by the European Commission under the Marie Curie Career Re-Integration Grant "TRANSFORM-EO" project for the completion of this work.

Edited by: D. Lawrence

\section{References}

Battrick, B.: The Changing Earth. New Scientific Challenges for ESA's Living Planet Programme, ESA SP-1304, ESA Publications Division, ESTEC, The Netherlands, 2006.

Carlson, T. N.: An overview of the "triangle method" for estimating surface evapotranspiration and soil moisture from satellite imagery, Sensors, 7, 1612-1629, 2007.

Carlson, T. N. and Boland, F. E.: Analysis of urban-rural canopy using a surface heat flux/temperature model, J. Appl. Meteorol., 17, 998-1014, 1978.

Carlson, T. N., Dodd, J. K., Benjamin, S. G., and Cooper, J. N.: Satellite estimation of the surface energy balance, moisture availability and thermal inertia, J. Appl. Meteorol., 20, 67-87, 1981.

Chauhan, N. S., Miller, S.m and Ardanuy, P.: Spaceborne soil moisture estimation at high resolution: amicrowave-optical/IR synergistic approach, Int. J. Remote Sens., 22, 4599-4646, 2003.

Chen, L., Tian, Y., Cao, C., Zhang, S., and Zhang, S. Sensitivity and uncertainty analysis of an extended ASM3-SMP model describing membrane bioreactor operation. J. Membrane Sci., 389, 99-109, 2012.

Dirmeyer, P. A.: The terrestrial segment of soil moistureclimate coupling, Geophys. Res. Lett., 38, L16702, doi:10.1029/2011GL048268, 2011.

Ellis, C. R. and Pomeroy, J. W.: Estimating sub-canopy shortwave irradiance to melting snow on forested slopes, Hydrol. Process., 21, 2581-2593, 1975. 
European Space Agency: Support to Science Element 2012 A pathfinder for innovation in Earth Observation, 41 pp., available at: http://due.esrin.esa.int/stse/files/document/STSE_ report_121016.pdf (last access: 10 July 2013), ESA, 2012.

Gillies, R. R. and Carlson, T. N.: Thermal remote sensing of surface soil moisture content with partial vegetation cover for incorporation into climate models, J. Appl. Meteorol., 34, 745-756, 1995.

Gillies, R. R., Carlson, T. N., Cui, J., Kustas, W. P., and Humes, K. S.: Verification of the "triangle" method for obtaining surface soil moisture content and energy fluxes from remote measurements of the Normalised Difference Vegetation Index (NDVI) and surface radiant temperatures, Int. J. Remote Sens., 18, 3145-3166, 1997.

Holvoet, K., van Griensven, A., Seuntjents, P., and Vanrollegham, P. A.: Sensitivity analysis for hydrology and pesticide supple towards the river in SVAT, Phys. Chem. Earth, 30, 518-526, 2005.

Johnson, J. S., Gosling, J. P., and Kennedy, M. C.: Gaussian process emulation for second-order Monte Carlo simulations, J. Stat. Plan. Inference, 141, 1838-1848, 2011.

Kennedy, M. C.: Description of the Gaussian processes model used in GEM-SA, GEM-SA Help Documentation, 2004.

Kennedy, M. C. and O'Hagan, A.: Bayesian calibration of computer models, J. Roy. Stat. Soc. Ser. B, 63, 425-464, 2011.

Kennedy, M. C., Butler Ellis, M. C., and Miller, P. C. H.: BREAM: A probabilistic Bystander and Resident Exposure Assessment Model of spray drift from an agricultural boom sprayer, Comput. Electron. Agr., 88, 63-71, 2012.

Kimeldorf, G. and Wahba, G.: Some results on Tchebycheffian spline functions, J. Math. An. Appl., 33, 82-95, 1971.

Kustas, W. and Anderson, M.: Advances in thermal infrared remote sensing for land surface modelling, Agr. Forest Meteorol., 149, 2071-2081, 2009.

Lockart, N., Kavetski, D., and Franks, S. W.: On the role of soil moisture in daytime evolution of temperatures, Hydrol. Process., 27, 3896-3904, doi:10.1002/hyp.9525, 2012.

Nossent, J., Elsen, P., and Bauwens, W.: Sobol's sensitivity analysis of a complex environmental model, Environ. Model. Softw., 26, 1515-1525, 2011.

Oakley, J. and O'Hagan, A.: Probabilistic sensitivity analysis of complex models: A Bayesian approach, J. Roy. Stat. Soc. Ser. B, 66, 751-769, 2004.

O'Hagan, A.: Curve fitting and optimal design for prediction (with discussion), J. Roy. Stat. Soc. Ser. B, 40, 1-42, 1978.

Olioso, A.: Simulation des echanges d'energie et de masse d'un convert vegandal, dans le but de relier ia transpiration et al photosyntheses anx mesures de reflectance et de temperature de surface, PhD Thesis, University de Montepellier II, 1992.

Olioso, A., Chauki, H., Courault, D., and Wigneron, J.-P.: Estimation of evapotranspiration and photosynthesis by assimilation of remote sensing data into SVAT models, Remote Sens. Environ., 68, 341-356, 1999.

Oliphant, A. J., Spronken-Smith, R. A., Sturman, A. P., and Owens, I. F.: Spatial variability of surface radiation fluxes in mountainous terrain, J. Appl. Meteorol., 42, 113-128, 2003.

Parry, H. R., Topping, C. J., Kennedy, M. C., Boatman, N. D., and Murray, A. W. A.: Bayesian sensitivity analysis applied to an Agent-based model of bird population response to landscape change, Environ. Model. Softw., 45, 1-12, 2012.

Petropoulos, G. P. and Carlson, T. N.: Retrievals of turbulent heat fluxes and soil moisture content by Remote Sensing, in: Ad- vances in Environmental Remote Sensing: Sensors, Algorithms, and Applications, Taylor and Francis, 556, 667-502, 2011.

Petropoulos, G., Carlson, T. N., and Wooster, M. J.: An Overview of the Use of the SimSphere Soil Vegetation Atmosphere Transfer (SVAT) Model for the Study of Land-Atmosphere Interactions, Sensors, 9, 4286-4308, 2009a.

Petropoulos, G., Carlson, T. N., Wooster, M. J., and Islam, S.: A Review of Ts/VI Remote Sensing Based Methods for the Retrieval of Land Surface Fluxes and Soil Surface Moisture Content, Adv. Phys. Geogr., 33, 1-27, 2009b.

Petropoulos, G., Wooster, M. J., Kennedy, M., Carlson, T. N., and Scholze, M.: A global sensitivity analysis study of the 1d SimSphere SVAT model using the GEM SA software, Ecol. Model., 220, 2427-2440, 2009c.

Petropoulos, G., Ratto, M., and Tarantola, S.: A comparative analysis of emulators for the sensitivity analysis of a land surface process model, 6th International Conference on Sensitivity Analysis of Model Output, 19-22 July 2010, Milan, Italy, on Procedia Social and Behavioral Sciences, Vol. 2, 7716-7717, 2010.

Petropoulos, G. P., Konstas, I., and Carlson, T. N.: Automation of SimSphere Land Surface Model Use as a Standalone Application and Integration with EO Data for Deriving Key Land Surface Parameters, European Geosciences Union, 7-12 April 2013, Vienna, Austria, 2013a.

Petropoulos, G., Griffiths, H. M., and Ioannou-Katidis, P.: Sensitivity Exploration of SimSphere Land Surface Model Towards its Use for Operational Products Development from Earth Observation Data, in: Advancement in Remote Sensing for Environmental Applications, edited by: Mukherjee, S., Gupta, M., Srivastava, P. K., and Islam, T., Springer, Chapter 14, 21 pp., in press, 2013b.

Petropoulos, G. P., Griffiths, H., and Tarantola, S.: Sensitivity Analysis of the SimSphere SVAT Model in the Context of EO-based Operational Products Development, Environ. Model. Softw., 49, 166-179, 2013c.

Petropoulos, G. P., Griffiths, H. M., and Tarantola, S.: Towards Operational Products Development from Earth Observation: Exploration of SimSphere Land Surface Process Model Sensitivity using a GSA approach, 7th International Conference on Sensitivity Analysis of Model Output, 1-4 July 2013, Nice, France, 2013d.

Piles, M., Camps, A., Vall-llossera, M., Corbella, I., Panciera, R., Rudiger, C., Kerr, Y. H., and Walker, J.: Downscaling SMOSDerived Soil Moisture Using MODIS Visible/Infrared Data, IEEE Trans. Geosci. Remote Sens., 49, 3156-3166, 2011.

Ratto, M., Tarantola, S., and Saltelli, A.: Sensitivity analysis in model calibration: GSA-GLUE approach, Comput. Phys. Comm., 136, 212-224, 2011.

Sabetraftar, K., Mackey, B., and Croke, B.: Sensitivity of modelling gross primary productivity to topographic effects on surface radiation: A case study in the Cotter River Catchment, Australia, Ecol. Model., 222, 795-803, 2011.

Saltelli, A., Tarantola, S., and Chan, K. P.-S.: A quantitative modelindependent method for global sensitivity analysis of model output, Technometrics, 41, 39-56, 1999.

Saltelli, A., Chan, K., and Scott, E. M.: Sensitivity analysis, in: Wiley Series in Probability and Statistics, Wiley, Chichester, 2000.

Santanello, J. A., Peters-Lidard, C. D., Kumar, S. V., Alonge, C., and Tao, W.-K.: A modelling and observational framework for diagnosing local land-atmosphere coupling on diurnal timescales, J. Hydrometeorol., 10, 577-599, 2009. 
Seneviratne, S. I., Corti, T., Davin, E. L., Hirschi, M., Jaeger, E. B., Lehner, I., Orlowsky, B., and Teuling, A. J.: Investigating soil moisture-climate interactions in a changing climate: A review, Earth Sci. Rev., 99, 125-161, 2010.
Song, X., Bryan, B. A., Paul, K. I., and Zhao, G.: Variance-based sensitivity analysis of a forest growth model, Ecol. Model., 246, 135-143, 2012. 